Dossiê - Para além do “ativismo judicial” e da “judicialização da política” DOI: $10.5433 / 2176-6665.2016 \mathrm{v} 21 \mathrm{~N} 1 \mathrm{P} 145$

\title{
As decisões JUdiciais e as políticas públicas SObre a educação no Estado de São Paulo
}

\author{
Lígia Barros DE Freitas ${ }^{1}$
}

\begin{abstract}
Resumo
$\mathrm{O}$ artigo tem como objetivo apresentar os resultados de um mapeamento das decisões judiciais sobre o direito à educação do Tribunal de Justiça de São Paulo, no período de 1998 a 2013. O trabalho aponta o tipo de ação (individual ou coletiva) proposta, o autor da ação e analisa os fundamentos das decisões judiciais. Além disso, trata de sua influência nas políticas públicas sobre a criação de vagas escolares na Educação Infantil, Fundamental e Média no Estado de São Paulo. Na sequência, compara os resultados com os obtidos nas pesquisas sobre decisões judiciais sobre direito à saúde. Concluímos que houve uma mudança institucional do Tribunal de Justiça de São Paulo em suas decisões, com sua maior receptividade no julgamento de ações coletivas referentes ao direito à educação.
\end{abstract}

Palavras-chave: Direito e política. Políticas públicas; Direito à educação: ações judiciais.

\section{JUdicial DECISIONS AND PUBLIC POLICIES ON EDUCATION IN THE State of São Paulo}

\begin{abstract}
The article aims to present the results of a mapping of the judicial decisions on the right to education of the São Paulo Court of Justice, from 1998 to 2013. This paper shows the type of action (individual or collective) which was proposed, the author of the action and analyzes the justifications of the judicial decisions. Moreover, it shows their influence on the public policy related to the creation of slots in the early

1 Doutora em Ciência Política pela Universidade Federal de São Carlos (UFSCar), Brasil. ligiadefreitas@ig.com.br
\end{abstract}


childhood education, primary education and secondary education in São Paulo State. Subsequently, we compare the results with those obtained in the researches on the judicial decisions concerning the right to health. We conclude that there was an institutional change of the São Paulo Court of Justice decisions, with its greater receptivity in the judgment of the collective action referring to the right to education.

Keywords: Law and politics. Public policies. Right to education: Lawsuits.

\section{INTRODUÇão ${ }^{2}$}

importância do Direito e do Poder Judiciário na vida social
brasileira, após a criação de novos mecanismos judiciais de acesso ao Judiciário pela Constituição de 1988, é objeto de estudo na Ciência Política e no Direito brasileiros.

Uma das linhas de pesquisa que traça uma perspectiva interdisciplinar entre a Ciência Política e o Direito, abordando como as decisões do Poder Judiciário e a atuação dos profissionais da área do direito afetam à política, concentra-se nos estudos sobre a judicialização de direitos sociais, que tratam como as políticas públicas são influenciadas pelas decisões judiciais.

Essas pesquisas se apropriaram do conceito de judicialização da política no sentido de expansão do Poder Judiciário no processo decisório das democracias contemporâneas, com a ampliação da área dos tribunais nas ações legislativas e executivas. Entretanto, parte delas considera essa expansão como positiva, como reflexo do ativismo político de agentes sociais e judiciais na produção da cidadania (CITTADINO, 2000; VIANNA; BURGOS, 2005), e algumas pesquisas atribuem a esse processo implicações negativas, correspondendo à face "politizada da justiça", com caráter corporativo e em substituição da sociedade civil na concretização dos seus direitos (ARANTES, 2002).

Em comum, buscam analisar e explicar como o Judiciário tem influenciado nos processos de formulação e implementação

2 Trata-se de uma versão modificada de texto apresentado originalmente no $38^{\circ}$ Encontro Anual da Anpocs em 2014. 
das políticas públicas nas áreas sociais, interferindo diretamente na agenda do Executivo. Nesse sentido, “a judicialização da política requer que operadores da lei prefiram participar da policy-making a deixá-la ao critério de políticos e administradores e, em sua dinâmica, ela própria implicaria papel político mais positivo da decisão judicial." (MACIEL; KOERNER, 2002, p.114).

As pesquisas que atribuem efeito positivo a esse processo, como o presente trabalho, atribuem ao conceito de judicialização da política o significado de uma relação de cooperação e complementariedade entre poderes na produção de decisões políticas, o mesmo dado por Vianna et al. (1999), onde o Judiciário participa como catalizador das expressões de grupos ou indivíduos que demandem por promoção de efetividade dos direitos fundamentais. (LOPES, 2006; VIANNA; BURGOS, 2005; TAYLOR, 2007; OLIVEIRA; NORONHA, 2011; OLIVEIRA; MARCHETTI, 2013; ENGELMANN; CUNHA FILHO, 2013).

Alguns estudos priorizam a mobilização do direito pelos legitimados a proporem as ações coletivas, com isso apontam o papel relevante dos membros do Ministério Público e da Defensoria Pública para a construção da cidadania, casos em que o Judiciário é visto como mais uma arena na disputa por direitos (VIANNA; BURGOS, 2005).

Opresenteestudo, mapeandoas decisões judiciais provenientes do Tribunal de Justiça de São Paulo sobre a obrigatoriedade de vagas escolares na Educação Infantil, Fundamental e Média, busca colaborar com a ampliação de pesquisas que tratam da interação do Poder Judiciário na formulação e implantação das políticas públicas. Nesse sentido, são analisados os fundamentos jurídicos dos juízes envolvidos no processo, a sua influência nas políticas públicas sobre a criação de vagas escolares na Educação Infantil, Fundamental e Média e quem ingressa em juízo pleiteando tal direito e o tipo de ação (individual ou coletiva) proposta. As perguntas que este estudo pretende responder 
são: 1) Os fundamentos das decisões das ações que pleiteiam direito à educação são os mesmos que nas ações sobre direitos à saúde? 2) Até que ponto as decisões judiciais de direito à educação influenciam na aplicação de políticas públicas? 3) Há diferença no padrão das decisões das ações coletivas que pleitearam direito à educação e as que demandaram direito à saúde?

Adota-se a perspectiva teórica do institucionalismo. Segundo uma nova agenda de pesquisa do institucionalismo histórico, as instituições são definidas como instrumentos distribucionais com implicações de poder. De tal modo, as regras, formais ou informais das instituições, acabam por distribuir poderes desiguais entre os atores. Ou seja, as organizações políticas influenciam no grau de poder que os atores podem ter sobre os resultados políticos (MAHONEY; THELEN, 2010). A análise dos processos judiciais que envolvem o direito à educação, sob esse enfoque teórico, possibilitará pesar a participação dos atores envolvidos na questão, a distribuição de poderes entre eles para os resultados políticos e jurídicos alcançados. Para Souza (2007), o institucionalismo histórico contribui para o debate sobre o papel das instituições na modelagem das preferências das decisões das políticas públicas.

Outra agenda de pesquisa do institucionalismo histórico explora a relação entre novas ideias políticas e configurações institucionais, analisando como as instituições mediam as ideias e os resultados políticos específicos (LEVI, 1991). As mudanças institucionais provocadas por novas ideias ocorrem na medida em que há uma mudança na distribuição de poder, provocando, paulatinamente, o abandono das pessoas e grupos aos velhos padrões institucionais. As mudanças são mais prováveis quando aumenta a eficiência dos indivíduos que a desejam, consequentemente, com a diminuição do poder de veto daqueles que são servidos pelos arranjos institucionais existentes. 
Dessa forma, o abandono das regras internalizadas, que nada mais são do que princípios morais capazes de encorajar as pessoas à obediência, ocorreria com a descoberta ou a criação de novos recursos pelos indivíduos que desafiam o sistema, ou ainda, com a deterioração dos recursos daqueles que definem os arranjos institucionais. $\mathrm{O}$ processo de mudança é um processo incremental, sendo mais provável que seja produto de decisões institucionais internas, que alteram, sutilmente, a distribuição de recursos, do que um processo totalmente reconstrutivo ou destrutivo (LEVI, 1991).

Essa última vertente contribuiu para pensar a apropriação, pelos atores envolvidos no processo, em particular, e pelos atores sociais, de modo mais amplo, dos novos mecanismos da Constituição de 1988 para a efetivação dos direitos e garantias fundamentais através do Judiciário e os fundamentos das decisões judiciais sobre as políticas públicas.

Segundo McCann (2010), a vantagem do institucionalismo histórico consiste em entender o fortalecimento judicial como um complexo processo que envolve diversos atores do Estado e da sociedade, e que os interesses devem ser entendidos em termos de visões e ideias emergentes. Nesse sentido, à abordagem do institucionalismo histórico é possível acrescer outros fatores para análise, como a motivação dos juízes, análise da interação estratégia das elites, mobilização de direitos feitos por indivíduos ou grupos para a efetivação de direitos, ou seja, essa abordagem tem se mostrado aberta ao exame de diferentes variáveis, trazendo uma maior complexidade para a análise da judicialização de direitos sociais.

No presente estudo, analisando as respostas do Poder Judiciário quando provocado e os tipos de ação pleiteando o direito à educação, são apontados alguns indícios de mobilização do direito pelo Ministério Público, cuja busca da realização de seus interesses e valores, acaba por promover a efetivação do direito à educação e a 
interferência na formulação de políticas públicas do Executivo. Ainda, o estudo sugere que os precedentes legais, principalmente com a criação de súmulas, como é o caso do direito de criança com menos de sete anos poder ser matriculada na primeira série, acabam por estimular o ingresso das ações judiciais particulares, dada a probabilidade maior de ganhos.

Não é o propósito do estudo a análise das variadas causas que conjuntamente explicariam melhor o fortalecimento dos tribunais na efetivação do direito social, como sugerido por McCann (2010), entretanto, o artigo traz a contribuição da análise das ações, vistas através do Judiciário. Com isso, na primeira seção serão abordados outros estudos já realizados sobre direito à educação; na sequência, os estudos da judicialização ao direito à saúde, que se torna relevante pelo fato deste também ser um direito social e por possibilitar a elaboração de um quadro comparativo analítico com as decisões sobre direito à educação. Na terceira seção, apresentamos os resultados da análise dos acórdãos sobre direito à educação provenientes do Tribunal de Justiça do Estado de São Paulo, entre o período de 1998 a 2013. ${ }^{3}$ Por fim, nas conclusões, são tecidas as comparações entre as ações pleiteando direito à educação e o direito à saúde, nos seguintes aspectos: tipos de ação, fundamentação e quem são os autores das ações.

\section{Os Estudos Sobre a Judicialização dos Direitos à Educação}

Os estudos que tratam da judicialização do direito à educação enfocam questões como o direito ao transporte público, a merenda, entre outros, e encontram-se em outras áreas do conhecimento, principalmente na Educação. ${ }^{4}$ São poucos os estudos que tratam especificamente da ampliação no número de vagas.

3 O ano de início da pesquisa (1998) foi estabelecido pela própria busca no site, que retornou com julgados a partir de 1998.

4 No google acadêmico são encontradas muitas obras em outras áreas do conhecimento. No Scielo somente foram encontradas duas obras, também em outra área do conhecimento, a 
No Direito, temos a contribuição de Lopes (2006), que em seu estudo enfoca as Ações Civis Públicas (ACPs) ajuizadas no Tribunal de Justiça de São Paulo (TJSP), entre o período de 1989 a 2003. Ele mostra a alteração dos pedidos da ACP: se até 1996 as ações tratavam de valores de mensalidades do ensino privado, a partir daí, os pleitos são dirigidos ao sistema escolar público (número de vagas, idade de matrícula, pagamento de escolas particulares por não haver vagas no ensino público). Conclui o autor que o Judiciário fica mais à vontade para julgar a favor de um indivíduo do que obrigar à revisão de políticas públicas e que os tribunais parecem insensíveis à discussão dos custos dos direitos.

Na Ciência Política, o estudo sobre a judicialização do direito à educação de Oliveira e Marchetti (2013) busca medir o impacto do Judiciário sobre a formação de agenda da política pública referente à disponibilização de vagas nas creches públicas no Município de São Paulo, mostrando a interação entre o Executivo municipal e o Judiciário. O estudo aponta que após a transferência dos recursos dessa área da Assistência Social para a Educação, com a criação do Fundeb (Fundo de Manutenção e Desenvolvimento da Educação Básica e de Valorização dos Profissionais da Educação), houve um crescimento de aproximadamente $7000 \%$ do número de matrículas feitas por ordem judicial, contra $75 \%$ no número de matrículas realizadas regularmente. Mostrando com isso que o Judiciário entende o direito à educação como direito inquestionável, que ainda desconsidera o argumento da "reserva do possível" e de que as prefeituras têm prazo ainda não concluído, segundo a Lei 11.494/2007 (que criou o Fundeb), para atenderem à demanda por matrículas.

Ademais, baseando-se em entrevistas realizadas com gestores da política de educação, os autores apontam que a judicialização do direito à educação tem chances iguais de sucesso tanto em demandas

saber: Chrispino e Chrispino (2008) e Scaff e Pinto (2016). 
individuais como nas coletivas e que Ministério Público e Defensoria Pública são acionados, diferentemente com o que ocorre com a judicialização do direito à saúde - na qual as demandas individuais têm maior chance de sucesso. Dessa forma, evita-se o ingresso das demandas coletivas, e há o predomínio de causas patrocinadas por advogados particulares.

Segundo Oliveira e Marchetti (2013, p. 17) na "judicialização da educação infantil no município de São Paulo, pode-se observar que o Executivo municipal age por meio da "estratégia política" lidando tanto com o atendimento individual como o coletivo", ou seja, ao reagir às decisões judiciais, o Executivo municipal promove políticas públicas que beneficiam, além das partes envolvidas no processo, um conjunto de cidadãos. Elencam, ainda, que o Executivo não se vale de "estratégia judicial" preventiva, por não contar com um estoque de vagas em creches, e nem de estratégia protelatória, pois, na maioria das vezes, precisa dar respostas urgentes, cumprindo liminares concedidas pelo Judiciário.

\section{Os Estudos sobre a Judicialização dos Direitos à SAúde}

Nesta seção é apresentada a revisão da literatura sobre direito à saúde, a fim de ter uma base para a análise e comparação do padrão das decisões judiciais sobre direito à educação.

Figueiredo (2008), responsável por um balanço dos estudos sobre o controle das políticas públicas pelo Judiciário, na área do Direito, levantou as questões que permeiam a discussão: 1 ) a violação ao princípio da separação de poderes, quando o Judiciário ao conhecer a violação de direitos invade a esfera de competência atribuída aos demais poderes, incorrendo em inconstitucionalidade; 2) a falta de competência do Poder Judiciário para acolher ou formular políticas públicas alternativas, papel que deveria ser privativo do poder eleito, 
democrático, e não do Judiciário; 3) o conflito das decisões judiciais com o orçamento público, quando cria ou altera despesas regularmente estabelecidas pelos poderes ou autoridades competentes e 4) os limites do papel do Judiciário na prestação da justiça distributiva e equitativa.

Segundo Lopes (2006), as decisões do Judiciário envolvendo a necessidade de políticas públicas ${ }^{5}$ são as provenientes das ações que reivindicam benefícios sociais ou individuais coletivamente fruíveis. Esses casos requerem decisões que, além de reconhecer um direito subjetivo, como o da educação, ordenem a obrigação de fazer ou prover um serviço público contínuo, ininterrupto. $\mathrm{O}$ autor aponta que essas novas demandas envolvem um problema de justiça distributiva e da legitimidade do sistema normativo. A questão de justiça distributiva diz respeito à alocação ou apropriação individual de recursos comuns, sendo que um sistema jurídico e político incapaz de prover uma distribuição justa e justificável perde a legitimidade.

Como a questão de justiça distributiva implica em apropriação de recursos comuns, uma das problematizações levantadas pela literatura sobre decisões judiciais que envolvem políticas públicas diz respeito à justiça das decisões individuais. As pesquisas observam que as decisões que pleiteiam direito à saúde decorrem mais de ações individuais do que coletivas. Parte da literatura vê como virtuosas as ações individuais, pois garantem o direito constitucional à saúde; entretanto, outros estudos ressaltam o aspecto negativo, pois não significam a positivação de direitos, mas a concessão de privilégios àqueles que possuem recursos (informacionais, financeiros) para sustentar uma demanda contra o Estado (OLIVEIRA; NORONHA, 2011).

5 Foi adotada neste artigo a definição de Souza (2007) de política pública. "Pode-se resumir a política pública como campo do conhecimento que busca colocar o 'governo em ação' e/ou analisar essa ação (variável independente) e, quando necessário, propor mudanças ao rumo ou curso dessas ações (variáveis dependentes)." (SOUZA, 2007, p. 69). Segundo a autora, ainda, a formulação de políticas públicas constitui-se no estágio que os governos democráticos traduzem seus propósitos e plataformas eleitorais em programas e ações. 
Outras pesquisas assinalam o predomínio nos tribunais brasileiros de uma cultura jurídica avessa ao direito moderno e aos seus princípios de impessoalidade, burocracia, previsibilidade e universalidade. Esses trabalhos mostram a relutância do Poder Judiciário brasileiro em decidir favoravelmente nas ações coletivas para a criação de políticas públicas, situação inversa àquela ocorrida nas causas individuais em que se pleiteiam direitos constitucionais, nas quais prevaleceram decisões favoráveis ao demandante (LOPES, 2006; FANTI, 2010; OLIVEIRA; NORONHA, 2011). Para Lopes (2006), a razão para isso se encontra na doutrina constitucional brasileira baseada no conceito de direito subjetivo individual, não incorporando o problema central de um regime democrático: o da universalidade e isonomia abstrata.

Para além dessa dicotomia de interpretação, Oliveira e Noronha (2011), em detalhado estudo sobre as demandas judiciais que pleiteiam direito à saúde, sinalizam que, apesar das controvérsias, o ativismo judicial tem alcançado efeitos positivos na criação de boas políticas públicas, interferindo diretamente na agenda do Executivo. Após inúmeras vitórias dos demandantes individuais que pleitearam medicamentos e suplementos médicos, a própria administração pública, a fim de limitar as ações em que era demandada, respondeu às decisões judiciais com a elaboração e implantação de um serviço de triagem, responsável por analisar a possibilidade de distribuição de remédios ainda não fornecidos pelo Sistema Único de Saúde (SUS), bem como com a introdução de um protocolo clínico para novos remédios, criando dessa maneira uma política pública de distribuição de medicamentos regulares para todos os pacientes na mesma situação.

Os autores apontam como as decisões judiciais individuais favoráveis à distribuição de medicamentos e suplementos médicos alcançaram um efeito coletivo, estimulando a criação de política pública pelo Executivo e, com isso, resolvendo o problema de justiça 
distributiva, na medida em que deixa de ser um privilégio para fazer valer o princípio de equidade.

Há pesquisas sobre a judicialização dos direitos à saúde que abordam o papel e os argumentos dos atores envolvidos no processo judicial. Para Vianna e Burgos (2005), o Direito e suas instituições tornaram-se importantes instâncias de promoção da integração social. A sociedade civil torna-se a comunidade de intérpretes, utilizando-se dos instrumentos fornecidos pela Constituição de 1988, como ACP. $\mathrm{O}$ acesso à Justiça adquire o status de um dos tópicos principais das políticas públicas. Especificamente sobre o estudo da ACP ajuizada pelo Ministério Público, pleiteando o fornecimento gratuito de medicamentos para o Estado e o Município do Rio de Janeiro, os autores apontam a relevância do Ministério Público e da Defensoria Pública para esse tipo de ação, bem como nos argumentos de que o direito à saúde é um direito fundamental e autoaplicável.

Engelmann e Cunha Filho (2013) focam a importância das doutrinas jurídicas que fundamentam as demandas judiciais e a resposta do Poder Judiciário em casos representativos de ações que demandam políticas públicas. A justificativa encontra-se no fato de que as doutrinas jurídicas e os confrontos de argumentos utilizados pelas partes envolvidas na demanda são definidores do "papel do Estado" e do "interesse público". Nesse sentido, após a análise das decisões do Supremo Tribunal Federal (STF) nas ações que versavam sobre o direito à saúde, percebem uma alteração dos argumentos legais da mais alta Corte: no início dos anos 1990, o Supremo tratava o tema como uma questão de mera subsunção de dispositivo constitucional; a partir do início dos anos 2000, as decisões são mais bem fundamentadas na doutrina constitucional, classificando o direito à saúde como um direito subjetivo público que o Estado tem o dever de garantir aos hipossuficientes; e a partir de 2007, as decisões indeferindo o fornecimento de concessão gratuita de medicamentos 
ou tratamentos pleiteados com base em outros argumentos, como o princípio de separação de poderes e limites orçamentários do Estado, tornam-se mais frequentes.

A literatura sobre as decisões judiciais que influenciam a aplicação das políticas públicas na saúde apresentou algumas conclusões que serviram de roteiro para a presente pesquisa. Com isso, o presente estudo se ateve nas seguintes questões, para possibilitar uma análise comparativa: 1) a concessão do direito pleiteado é uma forma de realização da justiça distributiva?; 2) há uma maior aceitação das demandas individuais quando comparadas com as demandas coletivas?; 3) as decisões judiciais promovem uma alteração da agenda do Executivo em relação à política pública de atendimento ao direito pleiteado?

\section{A Análise dos Acórdãos sobre Direito à Educação}

Na pesquisa realizada no site do Tribunal de Justiça de São Paulo foram obtidos 299 julgados, sendo que 120 tratavam de ações sobre direito à educação pleiteando vagas/matrícula no ensino infantil, fundamental e médio. ${ }^{6}$ As decisões analisadas consistem em acórdãos provenientes de apelações de ações individuais (Mandados de Segurança, Ação Ordinárias de Obrigação de Fazer) e de ações coletivas (Ações Civis Públicas), propostas em diferentes comarcas do Estado de São Paulo.

6 O estudo não contemplou a análise de causas pleiteando o direito à vaga para portadores de necessidade especial, pois o resultado da busca realizada no site, com as palavras vagas e educação não foram suficientes para retornar todas as ações sobre o tema, sendo relatadas somente duas. Na primeira, no acórdão de 2009, o Tribunal reforçou a sentença de primeiro grau, garantindo o atendimento à educação especializada ao portador de deficiência, por entender que a norma constitucional não possui caráter programático, mas sim norma de eficácia plena, cuja violação implica ilegalidade, passível de ser sanada pelo Judiciário. No outro processo, a decisão do TJSP, proferida em 2013, igualmente mencionando o artigo constitucional que assegura atendimento educacional especializado aos portadores de deficiência, reafirmou a garantia do aluno autista à bolsa especial, assegurando a matrícula em escola especial privada, já que a Municipalidade não fornecia vagas na rede pública. 
Essas ações modificaram-se no período analisado. Entre 1998 a 2001, prevaleceram litígios individuais demandando a obrigatoriedade de matricular menor de sete anos completos no ensino fundamental. No período de 2001 a 2013, predominaram os litígios individuais pleiteando a garantia de vagas no ensino infantil (creches e préescolas).

\section{Decisões ENVOLVENDO o ENSINO INFANTIL}

Os acórdãos que trataram da garantia de vagas no ensino infantil (creches e pré-escolas), a maior parte julgados entre 2001 e 2013, todos concedendo o direito pleiteado, justificaram que a educação é um direito constitucional fundamental e dever do Estado e da sociedade, garantidos tanto na Constituição Federal como no Estatuto da Criança e Adolescente (ECA). Ademais, os acórdãos fizeram referência à Lei de Diretrizes e Bases da Educação, Lei 9.394/96, no concernente ao princípio de igualdade de condições para o acesso e permanência na escola; bem como à obrigação do Estado de garantir o atendimento gratuito em creches e pré-escolas às crianças de zero a seis anos de idade. Outro fundamento presente em alguns julgados, a partir de 2008, foi em relação a não aplicação do poder discricionário do administrador público, pois não há prerrogativa de escolha, dado que ao Estado se impôs a obrigatoriedade de criar as condições objetivas para a educação infantil.

As decisões proferidas a partir de abril de 2011 passaram também a se apoiarem nas Súmulas 63 e 65 do TJ, publicadas pela Câmara Especial do TJSP. A primeira, sobre a obrigatoriedade do Município de providenciar imediata vaga em unidade educacional. A segunda, sobre a não violação dos princípios de separação e independência dos poderes, da isonomia, da discricionariedade administrativa e da anualidade orçamentária das decisões judiciais 
que determinam às pessoas jurídicas da administração direta a disponibilização de vagas em unidades educacionais ou o fornecimento de medicamentos, insumos, suplementos e transporte a crianças e adolescentes. ${ }^{7}$

Essas decisões foram proferidas na maior parte dos casos em processos de demanda individual, proposta pelas partes envolvidas, patrocinados por advogados. ${ }^{8}$ Nos anos de 2008 a 2010, o Ministério Público ingressou com Mandados de Segurança em defesa do direito à vaga na creche: no período de 2008 e 2009, foram três os casos, pleiteando na mesma ação o direito de mais de uma criança; em 2010, houve o ingresso de um Mandado de Segurança em defesa do direito à vaga em creche de uma criança.

O tema foi objeto de ações em outros Estados do país, ganhando muito importância em 2009, quando se tornou questão de Repercussão Geral no Supremo Tribunal Federal (STF), através de um recurso interposto pelo Município de Santa Catariana. ${ }^{9}$ No presente

7 “Súmula 63: É indeclinável a obrigação do Município de providenciar imediata vaga em unidade educacional a criança ou adolescente que resida em seu território." [...] "Súmula 65: Não violam os princípios constitucionais da separação e independência dos poderes, da isonomia, da discricionariedade administrativa e da anualidade orçamentária as decisões judiciais que determinam às pessoas jurídicas da administração direta a disponibilização de vagas em unidades educacionais ou o fornecimento de medicamentos, insumos, suplementos e transporte a crianças ou adolescentes" (SÃO PAULO, 2016).

8 A pesquisa realizada no site do TJSP não permite saber se o advogado é um Defensor Público ou particular.

9 Descrição do Verbete: “A Repercussão Geral é um instrumento processual inserido na Constituição Federal de 1988, por meio da Emenda Constitucional 45, conhecida como a "Reforma do Judiciário". O objetivo desta ferramenta é possibilitar que o Supremo Tribunal Federal selecione os Recursos Extraordinários que irá analisar, de acordo com critérios de relevância jurídica, política, social ou econômica. $\mathrm{O}$ uso desse filtro recursal resulta numa diminuição do número de processos encaminhados à Suprema Corte. Uma vez constatada a existência de repercussão geral, o STF analisa o mérito da questão e a decisão proveniente dessa análise será aplicada posteriormente pelas instâncias inferiores, em casos idênticos. A preliminar de Repercussão Geral é analisada pelo Plenário do STF, através de um sistema informatizado, com votação eletrônica, ou seja, sem necessidade de reunião física dos membros do Tribunal. Para recusar a análise de um RE são necessários pelo menos 8 votos, caso contrário, o tema deverá ser julgado pela Corte. Após o relator do recurso lançar no sistema sua manifestação sobre a relevância do tema, os demais ministros têm 20 dias para votar. As abstenções nessa votação são consideradas como favoráveis à ocorrência de repercussão geral 
momento, a causa paradigma aguarda julgamento da questão constitucional sobre a auto aplicabilidade do artigo 208, inciso IV da Constituição Federal, ou seja, sobre a imediata eficácia do artigo constitucional sobre a exigência de vagas para crianças de 0 a 5 anos em creches e pré-escolas. Ingressaram na causa paradigma como a amicus curiae, ${ }^{10}$ além do Município de São Paulo, o Município do Rio de Janeiro e Abrinq pelos direitos da Criança e do Adolescente. ${ }^{11}$

O assunto também foi objeto de Ações Civil Públicas no Estado de São Paulo. A primeira instância do Judiciário paulista começou a julgar favoravelmente as Ações Civis Públicas, com a condenação dos municípios à criação de um número significativo de vagas na educação infantil, através de ampliação das creches existentes ou de construção de novas, o que foi confirmado pelo TJSP, em grau recursal, em dois recursos em 2013.

Um desses casos, proposto pelo Ministério Público, foi a condenação do Município de Nhandeara à obrigação de construir nova creche ou ampliar a existente para criar 70 novas vagas, atendendo a demanda de crianças de 6 anos de idade residentes na cidade, no prazo de seis meses e a culminação de multa diária em caso de descumprimento.

O caso mais emblemático foi a condenação do Município de São Paulo, em 16/12/2013, resultante de duas Ações Civis propostas por organizações que compõem o Movimento Creche para Todos, na criação de 150 mil novas vagas em educação infantil, até 2016, bem como na apresentação de cronograma da sua execução, ou seja, decisão

na matéria." (BRASIL, 2014a).

10 Descrição do Verbete: "Amigo da Corte". Intervenção assistencial em processos de controle de constitucionalidade por parte de entidades que tenham representatividade adequada para se manifestar nos autos sobre questão de direito pertinente à controvérsia constitucional. Não são partes dos processos; atuam apenas como interessados na causa. Plural: Amici curiae (amigos da Corte) (BRASIL, 2014a).

11 O último andamento processual registrado na página do STF é de 28/08/2014, data em que os autos foram para as mãos do relator, para a elaboração de seu voto. (BRASIL, 2014a). 
que intervém diretamente na agenda do Poder Executivo. $\mathrm{O}$ acórdão do TJ, que reformou a decisão de primeiro grau, também determinou a criação de um comitê de fiscalização do cronograma composto pela coordenadoria da infância do TJ, Defensoria e Ministério Público. De forma inédita, a decisão também mencionou o respeito aos critérios de padrão básicos de qualidade, como limites de alunos por educador.

Anteriormente ao julgamento, através de audiência pública, a primeira que ocorreu no Tribunal de Justiça de São Paulo, o Judiciário paulista promoveu o debate sobre a situação de violação ao direito à educação infantil em creches e pré-escolas no município de São Paulo. Por essa via, o Judiciário obteve informações e propostas para elaboração de um plano de expansão de vagas, das entidades que participaram da audiência, dentre elas, o Grupo de Trabalho Interinstitucional sobre Educação Infantil (GTIEI). ${ }^{12}$

A maior receptividade do Poder Judiciário Paulista, em primeiro e segundo grau, julgando procedente as demandas das Ações Civis Públicas, que tratam da criação de vagas para o ensino infantil (creches e pré-escolas), apontam para a mudança incremental dentro do próprio Judiciário. Demostra uma maior efetividade do Ministério Público em relação ao direito à educação e uma mudança de entendimento dos julgadores, que passaram a discutir em suas decisões, além dos direitos constitucionalmente previstos, questões de direito administrativo, para concluir que a questão não se inclui no poder discricionário do administrador. Direito à educação, segundo esse entendimento, não é prerrogativa de escolha do Estado, é obrigação legal. A Súmula 67 do TJSP invoca também as questões de separação e independência dos poderes.

12 O GTIEI é formado pela Ação Educativa Assessoria, Pesquisa e Informações, pela Defensoria Pública do Estado de São Paulo, pelo Grupo de Atuação Especial da Educação (GEDUC) do Ministério Público do Estado de São Paulo, por Rubens Naves Santos Jr e Hesketh -Escritórios Associados de Advocacia e pelo Grupo de Trabalho de Educação Nossa São Paulo (AÇÃO EDUCATIVA, 2014). 
Em primeiro grau, apenas duas decisões proferidas em ações individuais indeferiram o direito às vagas nas creches, alegando questões orçamentárias, porém, ambas foram reformadas pelo TJSP sob os fundamentos já expostos.

\section{Decisões envolvendo o ensino fUNDAMENTAL e MÉdio}

Entre 1998 e 2001, dos 67 Mandados de Segurança pleiteando a matrícula de menor em escola pública antes de completado sete anos de idade, apenas dois foram indeferidos em primeiro grau. ${ }^{13} \mathrm{~A}$ fundamentação do indeferimento levava em conta um dispositivo da Constituição do Estado de São Paulo que permitia a matrícula, desde que atendida à demanda por vagas de crianças com sete anos e se houvesse vagas remanescentes. Entretanto, o TJSP os reformulou, argumentando que a menção feita pela Carta Estadual às crianças de sete anos não excluía o direito subjetivo, líquido e certo, das crianças de seis anos à matrícula, diante da obrigação do Poder Público ao provimento de vagas em número suficiente à demanda do ensino fundamental obrigatório.

Nos demais acórdãos, nos quais as sentenças dos juízes de primeiro grau foram mantidas, predominou o fundamento jurídico que a Constituição Federal qualifica a educação como um dos direitos fundamentais da pessoa e dever do Estado e da família, devendo ser promovida e incentivada com a ajuda da coletividade, com vistas ao exercício pleno da cidadania. Outro embasamento legal foi no ECA, que dispõe sobre a proteção integral à criança e ao adolescente, atribuindo tal dever à família, comunidade, sociedade em geral e Poder Público, devendo assegurar com absoluta prioridade, a efetivação dos direitos à vida e à saúde.

13 Outros dois recursos foram parcialmente providos para manter a ordem de matricular os menores de sete anos, entretanto, reformar a condenação de honorários advocatícios. 
Desses 67 mandados de seguranças, 65 foram propostos por advogados que patrocinaram o interesse de uma criança, a quem tinha sido negado o direito de se matricular, e os outros três foram propostos pelo Ministério Público, na defesa de mais de uma criança em cada um dos mandados.

O tema também foi objeto de apelação interposta pela Fazenda Pública, perdedora em uma Ação Civil Pública proposta pelo Ministério Público, para modificar a sentença que garantiu o ensino gratuito a todos os alunos que completassem 07 anos no ano de ingresso da ação (1997). O Tribunal de Justiça de São Paulo, em consonância de como já vinha decidindo o assunto, julgou improcedente o recurso, confirmando a obrigatoriedade da garantia.

Outras causas, em menor número, demandaram vagas no ensino fundamental e médio. Todas foram deferidas em primeiro grau e confirmadas pelo TJSP. Há o registro de uma Ação Civil Pública, proposta pelo Ministério Público, objetivando a condenação do Estado de São Paulo na obrigação de matricular jovens e adultos maiores de 20 anos de idade no ensino médio regular da rede pública estadual, oferecendo as respectivas vagas. A ação foi julgada procedente em primeira instância e confirmada pelo Tribunal, sob a fundamentação de que a Resolução 164/97 da Secretaria Estadual da Educação daquele Estado era inconstitucional, pois restringia a matrícula às pessoas com idade superior a 20 anos na primeira série do Ensino Médio regular, o que vai de encontro ao dever do Estado de garantir a universalização do ensino médio gratuito.

Um julgado de 2012, mantendo a sentença de primeiro grau, destacou-se por exigir que a vaga no ensino médio fornecida ao aluno fosse em escola próxima a sua residência. Segundo o acórdão, assegurar o direito ao ensino não significava apenas oferecer uma vaga qualquer na rede pública, mas efetivamente propiciar as condições para que $\mathrm{o}$ aluno possa frequentar as aulas, evidenciando com isso o direito à 
matrícula na escola mais próxima à residência do aluno, sob pena de inviabilizar o próprio acesso à educação.

Tanto em relação ao direito às vagas em creches quanto ao direito do menor de sete anos de se matricular no ensino fundamental, o número das demandas individuais, propostas pelo Ministério Público ou pelos interessados, contra escolas ou Municípios, foi maior do que as demandas coletivas. Além disso, em todo o período, os juízes de primeiro grau foram receptivos ao reconhecimento do direito pleiteados, assim como o TJSP, que não negou em nenhuma decisão o direito à educação e, ainda, modificou as poucas sentenças monocráticas que haviam negado o direito à matrícula.

\section{Conclusões}

O estudo evidencia que o Poder Judiciário é uma importante instituição na modelagem das decisões sobre as políticas públicas referentes ao direito constitucional à educação. Interfere diretamente na obrigação de prestação do serviço pelo Estado, seja ordenando de forma individual, nas decisões em Mandado de Segurança ou em Ação Ordinária, seja por meio das decisões coletivas, em Ações Civis Públicas.

A judicialização do direito à educação no Estado de São Paulo aponta que, apesar de contar com um número muito grande de ações individuais e propostas diretamente pelos interessados, assim como nas ações que pleiteiam direito à saúde, há uma mudança institucional do Judiciário pela maior aceitação de ação coletiva, bem como dos próprios atores que mobilizam o direito, como o Ministério Público e organizações civis.

A mudança ocorreu de forma incremental, primeiro com a propositura e aceitação de ações individuais, para, na sequência, os atores sociais valerem-se das ações coletivas, influenciados com novas 
ideias e necessidade, buscando resolver melhor a questão da justiça distributiva, com a alocação do recurso público para o atendimento de todos os cidadãos que se encontram na mesma situação.

A judicialização do direito à educação, para além de influenciar a agenda da política pública, assim como ocorreu na judicialização dos direitos à saúde, também interviu em duas outras fases: na de formulação, quando fixou os parâmetros que a expansão da rede pública de creches deveria seguir na cidade de São Paulo, e na fase de implementação, quando determinou que instituições jurídicas (Coordenadoria da Infância do TJSP, Ministério Público, Defensoria Pública) e a sociedade civil (organizações que compõem o Movimento Creche para Todos) fiscalizassem a implementação da política púbica.

Em outra questão, sobre o direito da criança ser matriculada no ensino fundamental antes de completar sete anos, o Poder Judiciário paulista intervém na formulação das políticas públicas, antes mesmo que a questão seja judicializada, da mesma forma que ocorreu com direito à saúde, cujos estudos apontaram a elaboração de um serviço de triagem que teve alcance coletivo (FANTI, 2010; OLIVEIRA; NORONHA, 2011). O TJSP, através da elaboração de precedentes jurisprudenciais de questões envolvendo direito à educação, constituiu uma consolidada base do seu entendimento, o que ocasionou o raleamento desse tipo de demanda, que era muito comum entre os anos de 1998 e 2000. Isso sugere que as instituições públicas começaram a se adiantar em fornecer vagas para menores nesta situação, sabendo que seriam condenadas caso não o fizessem.

\section{REFERÊNCIAS}

AÇÃO EDUCATIVA. TJ-SP determina a criação de um Comitê de Monitoramento do Plano de Ampliação da Rede de Educação Infantil na cidade. 2014. Disponível em: <http:// www.acaoeducativa.org.br/index.php/educacao/51-acao-na-justica/10005002-tj-spdetermina-a-criacao-de-um-comite-de-monitoramento-do-plano-de-ampliacao-darede-de-educacao-infantil-na-cidade>. Acesso em: 23 maio 2016. 
ARANTES, Rogério Bastos. Ministério Público e política no Brasil. São Paulo: Sumaré, 2002.

BRASIL. Supremo Tribunal Federal. AI 761908 - Agravo de Instrumento. Fundação Abrinq Pelos Direitos Da Criança E Do Adolescente e o Município do Rio de Janeiro requerem suas admissões no feito na qualidade de amici curiae. Relator: Min. Luiz Fux. DJE no 149, 1 ago. 2014a. Disponível em: $\quad<$ http://www.stf.jus.br/portal/processo/verProcessoAndamento.asp? numero $=761908 \&$ classe $=$ AI\&origem $=\mathrm{AP} \&$ recurso $=0 \&$ tipoJulgamento $=\mathrm{M}>$. Acesso em: 21 maio 2016.

BRASIL. Supremo Tribunal Federal. Glossário jurídico. Disponível em: <http://www. stf.jus.br/portal/glossario/verVerbete.asp?letra=A\&id=533>. Acesso em: 20 ago. 2014b.

CHRISPINO, Alvaro; CHRISPINO, Raquel S. P. A judicialização das relações escolares e a responsabilidade civil dos educadores. Ensaio, Rio de Janeiro, v. 16, n. 58, p. 9-30, jan./mar. 2008

CITTADINO, Gisele. Pluralismo, direito e justiça distributiva: elementos da filosofia constitucional contemporânea. Rio de Janeiro: Lúmen Júris, 2000.

ENGELMANN, Fabiano; CUNHA FILHO, Marcio Camargo. Ações Judiciais, conteúdos políticos: uma proposta de análise para o caso brasileiro. Revista de Sociologia e Políticas, Curitiba, v. 21, n. 45, p. 57-72, 2013.

FANTI, Fabíola. Políticas de saúde em juízo: um estudo sobre o município de São Paulo. 2010. 106 f. Dissertação (Mestrado em Ciência Política) - Faculdade de Filosofia, Letras e Ciências Humanas, Universidade de São Paulo, São Paulo, 2010.

FIGUEREIDO, Marcelo. O controle das políticas públicas pelo Poder Judiciário no Brasil: uma visão geral. Revista Eletrônica da Faculdade de Direito da PUC-SP, São Paulo, v. 1, p. 1-55, 2008. Disponível em: <http://revistas.pucsp.br/index.php/red/ issue/view/70 >. Acesso em: 20 jan. 2014.

LEVI, Margaret. Uma lógica da mudança institucional. Dados, Rio de Janeiro, v. 34, n. 1, p. 79-99. 1991.

LOPES, José Reinaldo de Lima. Direitos sociais teoria e prática. São Paulo: Método, 2006.

MACIEL, Débora Alves; KOERNER, Andrei. Sentidos da judicialização da política: duas análises. Lua Nova, São Paulo, n. 57, p. 113-133, 2002.

MAHONEY, James; THELEN, Kathllen Ann. Theory of gradual institucional change. In: (Ed.). Explaining institutional change: ambiguity, agency and Power. Cambridge: Cambridge University Press, 2010. 
McCANN, Michael. Poder Judiciário e mobilização do direito: uma perspectiva dos "usuários". Revista da EMARF, Cadernos Temáticos, Rio de Janeiro, p. 175-196, dez. 2010.

OLIVEIRA, Vanessa Elias; MARCHETTI, Vitor. O Judiciário e o Controle sobre as Políticas Públicas: a judicialização da educação no município de São Paulo. In: ENCONTRO ANUAL DA ANPOCS, 37., 2013, Águas de Lindóia. Anais... Disponível em: $\quad<\mathrm{http} / /$ www.anpocs.org/portal/index.php?option=com_content\&view $=$ article $\& \mathrm{id}=667 \% 3 \mathrm{Aanais}-\mathrm{do}-$ encontro-sps-mrs-e-gts- $\&$ catid $=1135 \% 3 \mathrm{~A} 37 \mathrm{o}$ encontro-anual-da-anpocs\&Itemid=459>. Acesso em: 21maio 2016.

OLIVEIRA, Vanessa Elias; NORONHA, Lincoln N. T. Judiciary-Executive Relations in Policy Making: The Case of Drug Distribution in the State of São Paulo. Brazilian Political Science Review, São Paulo, v. 5, n. 2, p. 11-46. 2011.

SÃO PAULO. Tribunal de Justiça. Súmulas. Disponível em: <http://www.tjsp.jus.br/ Institucional/Decanato/Noticias/Noticia.aspx?Id=10334>. Acesso em: 20 set. 2015.

SCAFF, Elisângela Alves da Silva; PINTO, Isabela Rahal de Rezende. O Supremo Tribunal Federal e a garantia do direito à educação. Revista Brasileira de Educação, Rio de Janeiro, v. 21, n. 65, 2016.

TAYLOR, Matthew M. O judiciário e as políticas públicas no Brasil. Dados, Rio de Janeiro, v. 50, n. 2, p. 229-257. 2007.

VIANNA, Luiz Werneck et al. A judicialização da política e das relações sociais no Brasil. Rio de Janeiro: Revan, 1999.

VIANNA, Luiz Werneck; BURGOS, Marcelo Baumann. Entre princípios e regras: cinco estudos de caso de Ação Civil Pública. Dados, Rio de Janeiro, v. 48, n. 5, p. 777843, 2005. 